\title{
Engineering ductile fracture in brittle-matrix composites
}

\author{
V. C. LI, T. HASHIDA \\ Advanced Civil Engineering Materials Research Laboratory, Department of Civil and Environmental \\ Engineering, University of Michigan, Ann Arbor, MI 48109-2125, USA
}

This letter describes a newly discovered phenomenon: ductile fracture in cementitious materials. The brittle nature of materials such as concrete and ceramics has prompted the development of various approaches to enhance their fracture toughness. Fibre reinforcement has been the common focus in the toughening of the brittle materials.

Two types of fracture have been observed to date in cementitious materials and ceramics: brittle and quasi-brittle fracture. Brittle fracture can be observed, for example, in hardened cement paste material. It is characterized by a very small microcrack zone at the crack tip (Fig. 1a), typically of submillimetre scale, low fracture energy of the order of $0.01 \mathrm{~kJ} \mathrm{~m}^{-2}$, and a linear load versus load-point displacement curve from a fracture test. Quasi-brittle fracture can be observed in concrete and in most fibre-reinforced cements or concretes (FRC). It is characterized by a bridging process zone in addition to the small microcrack zone at the crack tip (Fig. 1b). The bridging action provides additional energy absorption through aggregate and/or ligament bridging in concrete, and through fibre bridging in FRC, in the wake of the crack front. For quasi-brittle materials the fracture energy extends a large range, from $0.1 \mathrm{~kJ} \mathrm{~m}^{-2}$ in concrete to several $\mathrm{kJ} \mathrm{m}^{-2}$ in the case of FRC. Correspondingly, the process zone size extends from the $\mathrm{mm}$ scale to the $\mathrm{cm}$ scale. The load versus load-line displacement curve from a fracture test may involve a small non-linear region near the peak load, with a significant post-peak tension-softening behaviour. Research into quasi-brittle materials in the past decade has been extensive (see, for example $[1,2]$ for a recent collection of papers on the subject). It must be mentioned that the classification of the fracture characteristics for cementitious materials described above may also be applicable to current monolithic and fibre-reinforced ceramics.

(a)

(b)

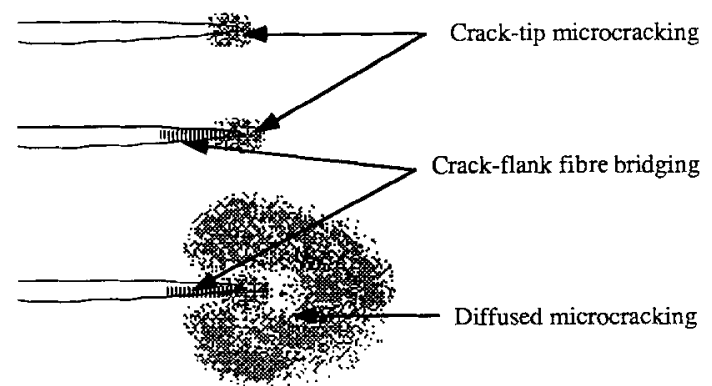

Figure 1 Fracture process zone in (a) brittle cement, (b) quasibrittle concrete and FRC, and (c) ductile SHCC.
This letter describes a new type of fracture in cementitious material which has previously not been observed. It may be labelled "ductile fracture" because it involves extensive off-crack-plane inelastic energy absorption, as shown schematically in Fig. 1c. However, unlike ductile metals, the present strain-hardening cementitious composite (SHCC) also involves extensive energy absorption on the crack plane. The total energy absorption level and the mechanisms involved place the SHCC in a separate class of materials in comparison to ordinary quasi-brittle fibre-reinforced concrete. The load versus load-line displacement curve from a fracture test is also expected to deviate from that of a quasi-brittle material.

This study attempted to achieve two objectives: first, to demonstrate the concept of ductile fracture in cementitious material using an SHCC designed, fabricated and tested at the ACE-MRL at the University of Michigan, and secondly, to provide a measure of the relative magnitude of energy absorption via the in-plane fibre bridging mechanism, and the off-plane strain-hardening mechanism. More details and further experimental results can be found in a companion paper [3].

All brittle materials may be made to exhibit pseudo-strain-hardening, provided proper fibre reinforcement is introduced to transfer the stress away from the matrix crack plane. Pseudo-strain-hardening has been demonstrated in a number of brittle matrix materials, including ceramics reinforced with continuous fibres (for example [4]) and in cements reinforced with continuous fibres (for example $[5,6])$, or with discontinuous randomly distributed fibres (for example $[7,8]$ ). The conditions under which pseudo-strain-hardening can occur in the last of these materials have recently been worked out $[9,10]$ based on micromechanics principles. An SHCC designed in this manner using polyethylene fibre exhibits a strain-hardening behaviour with strain capacity more than 100 times that of the matrix alone. Although the material strength is low, it serves as an excellent model material for studying the multiple cracking and ductile fracture processes, as the microcrack widths are sufficiently large to be visible without any sophisticated imaging needs. This means that real-time inelastic deformation can be followed and captured using an ordinary camera.

A material which strain-hardens implies that under strain-concentration, such as that at the tip of a notch, stress redistribution will occur so that localized fracture will be delayed. This suggests that 
in an SHCC an expanded zone of matrix cracking must surround the crack tip before crack propagation. This expanded zone is created by the stresstransfer capability of the reinforcing fibres, in a manner similar to that of the multiple-cracking process in a uniaxial tensile specimen. Of course, because the stress field surrounding the notch tip is different from the uniform stress field in a uniaxial tensile specimen, the resultant crack pattern will also be different. At any rate, such an extensive volumetric cracking process must involve considerable energy absorption, and it is this off-crack-plane inelastic energy absorption which may be expected to give rise to a ductile fracture behaviour.

When the crack-tip strain reaches the failure strain capacity of the SHCC, stable crack propagation will occur, although the crack flanks will still be bridged by fibres, and energy absorption by fibre pullout will take place. In an SHCC, therefore, the total composite fracture energy $\left(J_{c}\right)$ comes from two components: an off-crack-plane matrix-cracking component $J_{\mathrm{m}}$ and an on-crack-plane fibre-bridging component $J_{\mathrm{b}}$.

In the following we describe briefly an experimental programme which utilizes a uniaxial tensile test to determine $J_{\mathrm{b}}$, and a double-edge notched plate (DEN) and double cantilever beam (DCB) to determine the total fracture energy $J_{\mathrm{c}}$. The offcrack-plane fracture energy can then be deduced from the difference between $J_{\mathrm{c}}$ and $J_{\mathrm{b}}$.

The material selected for testing was a polyethylene fibre-reinforced mortar. Type I Portland cement, silica fume and superplasticizer were used to form the matrix of the composite with mix proportions of 1:0.20:0.03. The water/cement ratio was 0.27 . Polyethylene fibres of diameter $38 \mu \mathrm{m}$ and length $12 \mathrm{~mm}$ were introduced into the matrix. The fibre volume fraction was $2 \%$. It has been shown that the material system selected for this study can produce a strain-hardening behaviour with fibre volume fractions $>1 \%[8,10]$.

The dimensions of the uniaxial tensile (UT) specimens were $305 \mathrm{~mm} \times 76 \mathrm{~mm} \times 13 \mathrm{~mm}$. To measure the elongation, the relative displacement between two points along the specimen centre axis was monitored using linear variable differential transducers, with gauge length approximately $200 \mathrm{~mm}$. Fracture toughness tests were conducted on DEN specimens with the same dimensions as the $\mathrm{UT}$, and DCB specimens of two different sizes in order to examine the effect of specimen size on the fracture behaviour. The larger DCB specimens measured $361 \mathrm{~mm} \times 300 \mathrm{~mm} \times 61 \mathrm{~mm}$, and the smaller beams $153 \mathrm{~mm} \times 153 \mathrm{~mm} \times 35 \mathrm{~mm}$. The load $(P)$ and load-line displacement $(\delta)$ were continuously recorded during the fracture toughness tests. As described below, the total fracture energy was determined by means of the $J$-based technique [11]. In order to determine the $J$-value, a set of specimens with different notch lengths were tested for each type of specimen (see [11] for details of the testing procedure).

The stress-deformation curve obtained from the uniaxial tensile test is shown in Fig. 2. The designed composite exhibited a strain-hardening behaviour, as predicted by the micromechanical model [8-10]. Real-time observation showed that multiple cracking occurred with many sub-parallel cracks across the specimen during the strain-hardening behaviour. Two uniaxial tensile specimens were tested. The averaged strain at peak stress was approximately $3.5 \%$. Beyond peak stress, localized crack extension occurred, accompanied by fibre bridging. The fracture energy $\left(J_{\mathrm{b}}\right)$ due to the fibre bridging may then be computed by integrating the post-peak loaddisplacement relationship.

$$
J_{\mathrm{b}}=U / A_{\mathrm{lig}}
$$

where $U$ is the area under the post-peak load-crackopening curve and $A_{\text {lig }}$ is the net cross-sectional area. Test results on the DEN specimens were also used to determine $J_{\mathrm{b}}$. There was no significant difference in the $J_{\mathrm{b}}$ values of the unnotched and notched specimens; 11.8 and $14.8 \mathrm{~kJ} \mathrm{~m}^{-2}$ for the unnotched specimens, and 9.7 and $12.5 \mathrm{~kJ} \mathrm{~m}^{-2}$ for the DEN specimens. A theoretical model for the bridging fracture energy [12] based on the frictional fibre pullout mechanism predicts $J_{\mathrm{b}}$ to be $9.2 \mathrm{~kJ} \mathrm{~m}^{-2}$ (assuming an interfacial frictional bond strength of $1.02 \mathrm{MPa}$ [13] and a snubbing coefficient of 0.5 [12]). The higher value from experimental measurement may be due to the non-planar fracture behaviour, even in the notched specimens. This notion is also supported by the length of the post-peak stress-displacement curve being more than half the fibre length. In this preliminary study, an average of the $J_{\mathrm{b}}$ values $\left(12.2 \mathrm{~kJ} \mathrm{~m}^{-2}\right)$ is taken as an estimate of fibre bridging fracture energy, but this should be regarded as an upper bound of the true value, in light of the discussion above.

An example of load versus load-line displacement record of the DCB specimen is shown in Fig. 3 for the large-sized $D C B$ specimen. It is seen that, despite the presence of the deep notch, the material produces a significant strain-hardening behaviour subsequent to the bend-over point. Fig. 4 shows the damage evolution recorded for various load-line deformation values indicated in Fig. 3. In order to

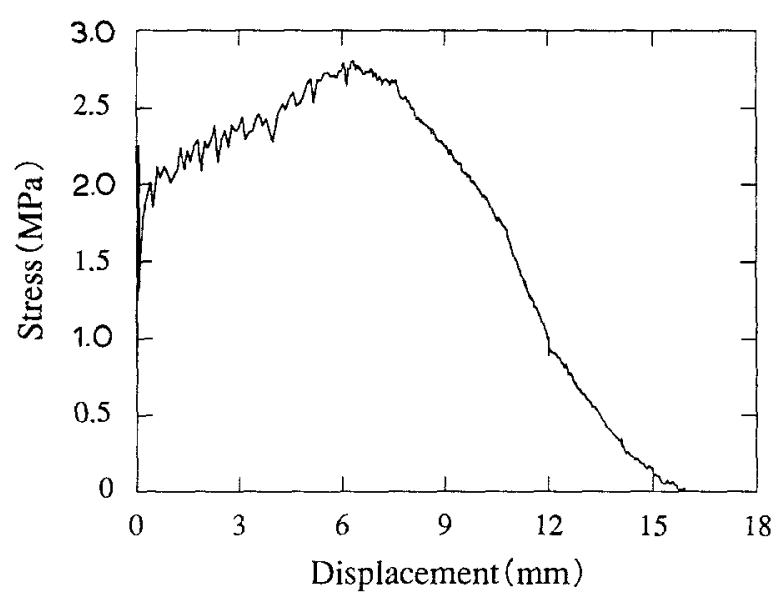

Figure 2 Stress-deformation relationship, gauge length $203 \mathrm{~mm}$. 


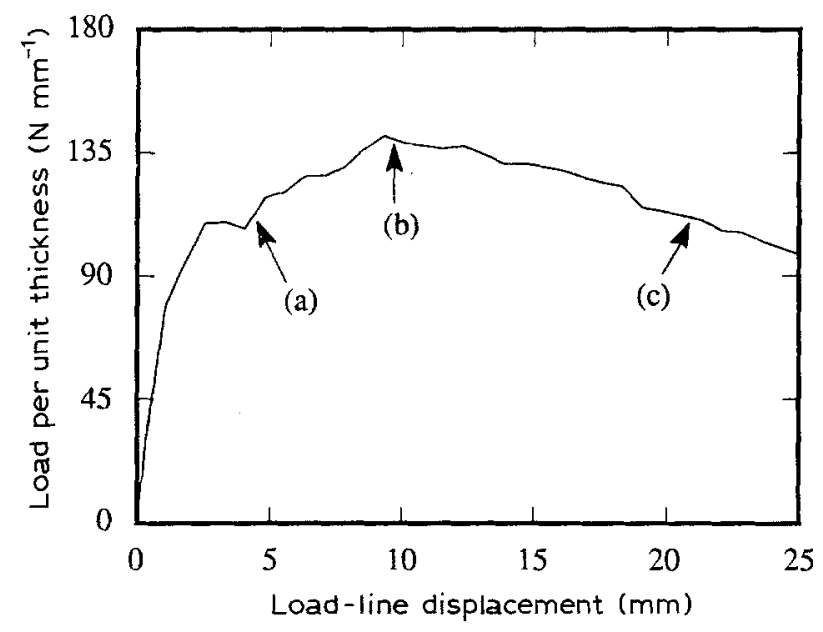

Figure 3 Load-displacement record for large DCB specimen.
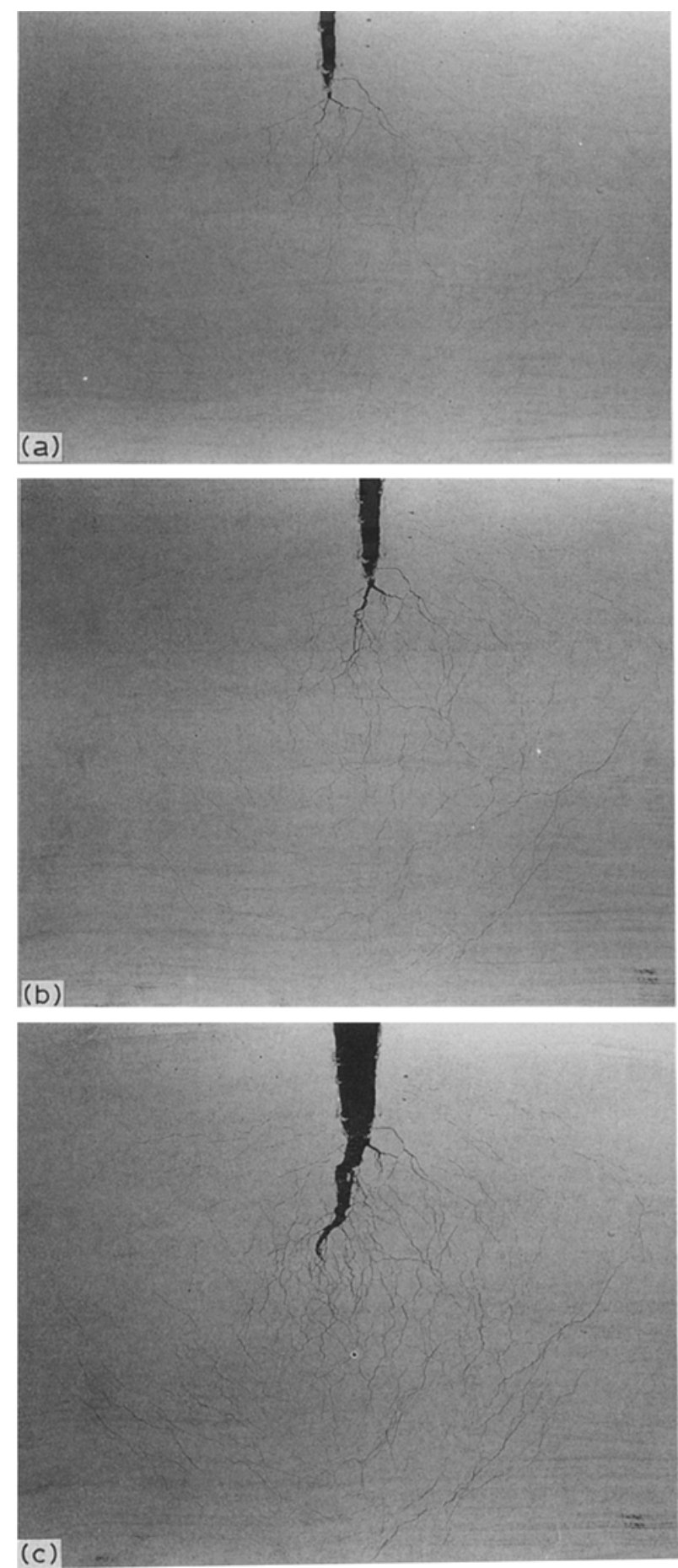

Figure 4 Damage evolution as a function of deformation: (a) $\delta=4.94 \mathrm{~mm}$, (b) $\delta=9.64 \mathrm{~mm}$ and (c) $\delta=21.12 \mathrm{~mm}$. facilitate the fracture observation, a white brittle paint (pure lime) was applied to the specimen surface. It is particularly noted that an extensive microcracking zone spread around the notch tip before the localized crack started to grow. The microcracking zone was seen to expand close to the beam outer boundary at the peak load, covering an area of more than $500 \mathrm{~cm}^{2}$ in the specimen. The final shape of the fully developed inelastic zone appeared to be like an onion with its base located near the notch tip. As clearly shown in Fig. 4, the strainhardening behaviour was attributed primarily to the extensive off-crack-plane microcracking process. In the following we deduce the fracture energy contribution $J_{\mathrm{m}}$ from the off-crack-plane microcracking by means of the $J$-based technique. The total fracture energy $\left(J_{\mathrm{c}}\right)$ can be evaluated from a set of load versus load-line displacement curves using the equation

$$
J_{\mathrm{c}}=\frac{1}{\left(a_{2}-a_{1}\right)} \int_{0}^{\delta}\left(\frac{P_{1}}{B_{1}}-\frac{P_{2}}{B_{2}}\right) \mathrm{d} \delta=\frac{S}{a_{2}-a_{1}}
$$

where $a$ and $B$ are the notch length and thickness, respectively. The subscripts 1 and 2 refer to the two different notch lengths, and $S$ is the area between the $P / B-\delta$ curves of the two specimens, as exemplified in Fig. 5 for the large DCBs. For the DEN, the notch length $a$ in Equation 2 is replaced by $2 a$. Fig. 6 summarizes the results of the $J$-based tests, showing the $J_{\mathrm{c}}$ values as a function of specimen size. The ligament length is selected as a representative specimen dimension. The area of the microcracking zone observed is also indicated in parentheses. $J_{\mathrm{m}}$ can be obtained from the difference between the $J_{c}$ and $J_{\mathrm{b}}$ values determined above. As shown in Fig. 6 , the $J_{\mathrm{m}}$ component increases with increasing specimen size because of the enlarged microcracking zone in larger specimens. In the large DCB specimens the $J_{\mathrm{m}}$ component amounts to $50 \%$ of the total fracture energy. For the present study a total fracture energy of $24 \mathrm{~J} \mathrm{~m}^{-2}$ was measured for the large specimens. However, it should be pointed out that the onionshaped inelastic zone has reached the full height of even the large specimens. The steady-state value of off-crack-plane energy absorption and the total

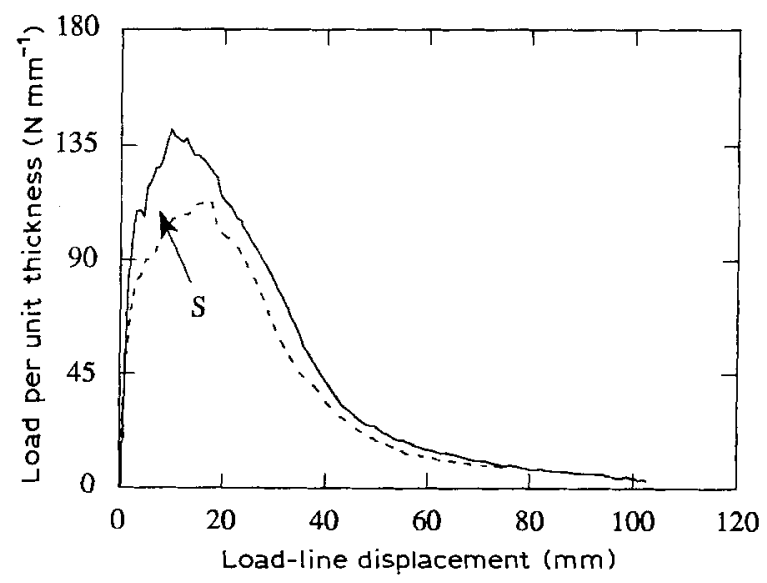

Figure $5 \mathrm{~J}$-based method. (-) $a_{1}=117 \mathrm{~mm}$ and $(--)$ $a_{2}=148 \mathrm{~mm}$. 


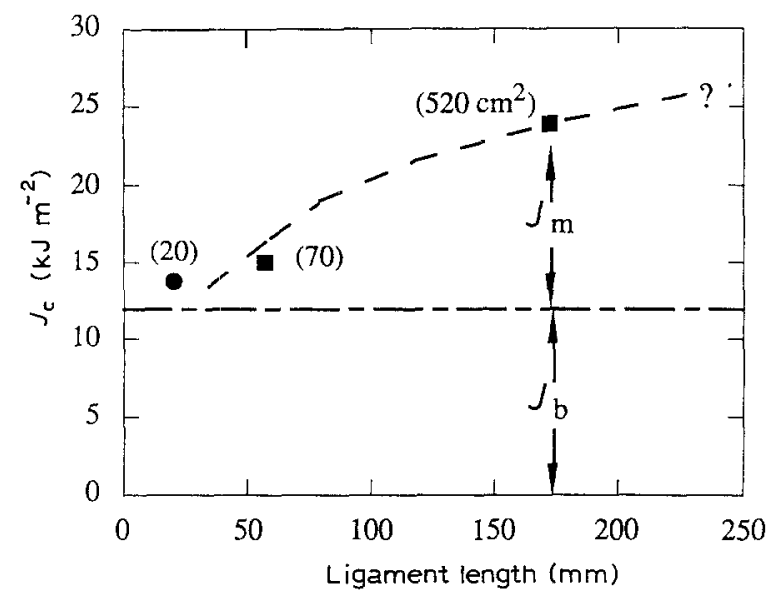

Figure 6 Summary of $J_{\mathfrak{c}}$ measurements, showing the contribution of $J_{\mathrm{m}}$ and $J_{\mathrm{b}}$ ( $(0)$ DEN specimen and (a) DCB specimen.

fracture energy may therefore be expected to be even higher. Further experimental study is needed to confirm this.

The mechanism of toughening enhancement observed and the materials design methodology used here should not be restricted to the cementitious material used in this study. A similar effect of the off-crack plane energy absorption may be expected for any discontinuous fibre-reinforced brittle-matrix composites, provided the material is properly reinforced with fibres so that strain-hardening occurs when loaded beyond its tensile cracking strength.

\section{Acknowledgements}

This work was supported by a grant from the National Science Foundation to the Advanced Civil
Engineering Materials Research Laboratory at the University of Michigan, Ann Arbor. The Program Manager at NSF is Dr Ken P. Chong. The authors acknowledge helpful discussions with Dr H. C. Wu and technical assistance from M. Maalej.

\section{References}

1. S. P. SHAH (editor), "Toughening mechanism in quasibrittle materials" (NATO ASI Series E), Vol. 195 (1991).

2. J. G. M. VAN MIER, J. G. ROTS and A. BAKKER (editors), "Fracture processes in concrete, rock and ceramics" (Chapman and Hall, 1991).

3. V. C. LI, T. HASHIDA and M. MAALEJ, in preparation.

4. D. B. MARShALL and A. G. EVANS, J. Amer. Ceram. Soc. 68 (1985) 225.

5. J. AVESTON, R. A. MERCER and J. M. SILLWOOD, in "Composites standards testing and design", Conference Proceedings of the National Physical Laboratory (IPC Science and Technology Press, Guildford, 1974) p. 93.

6. H. KRENCHEL and H. STANG, in Proceedings of the 2 nd International Symposium on Brittle Matrix CompositesBMC 2, Cedzyna, Poland, edited by A. M. Brandt and I. H. Marshall (1988), p. 20.

7. H. KRENCHEL, in "High performance fibre reinforced cement composites", edited by H. Reinhardt and A. Naaman (Chapman and Hall) in press.

8. V. C. LI and H. C. WU, ibid.

9. V. C. LI and C. K. Y. LEUNG, J. Engng Mech. in press.

10. V. C. LI and H. C. WU, Appl. Mech. Rev. submitted.

11. V. C. LI, C. M. CHAN and C. K. Y. LEUNG, Cement Concrete Res. 17 (1987) 441

12. V. C. LI, ASCE J. Mater. Civil Engng 4 (1992) 41.

13. V. C. LI, Y. WANG and S. BACKER, J. Composites 21 (1990) 132.

Received 3 March

and accepted 19 November 1992 